\title{
Mechanisms of increased risk of tumorigenesis in Atm and Brca1 double heterozygosity
}

\author{
Jufang Wang ${ }^{1}$, Fengtao Su', Lubomir B Smilenov², Libin Zhou' ${ }^{1}$, Wentao Hu ${ }^{1,3}$, Nan Ding ${ }^{1,3}$ and \\ Guangming Zhou ${ }^{*}$
}

\begin{abstract}
Background: Both epidemiological and experimental studies suggest that heterozygosity for a single gene is linked with tumorigenesis and heterozygosity for two genes increases the risk of tumor incidence. Our previous work has demonstrated that Atm/Brcal double heterozygosity leads to higher cell transformation rate than single heterozygosity. However, the underlying mechanisms have not been fully understood yet. In the present study, a series of pathways were investigated to clarify the possible mechanisms of increased risk of tumorigenesis in Atm and Brcal heterozygosity.
\end{abstract}

Methods: Wild type cells, Atm or Brca1 single heterozygous cells, and Atm/Brcal double heterozygous cells were used to investigate DNA damage and repair, cell cycle, micronuclei, and cell transformation after photon irradiation.

Results: Remarkable high transformation frequency was confirmed in Atm/Brca1 double heterozygous cells compared to wild type cells. It was observed that delayed DNA damage recognition, disturbed cell cycle checkpoint, incomplete DNA repair, and increased genomic instability were involved in the biological networks. Haploinsufficiency of either ATM or BRCA1 negatively impacts these pathways.

Conclusions: The quantity of critical proteins such as ATM and BRCA1 plays an important role in determination of the fate of cells exposed to ionizing radiation and double heterozygosity increases the risk of tumorigenesis. These findings also benefit understanding of the individual susceptibility to tumor initiation.

Keywords: heterozygosity, haploinsufficiency, tumorigenesis, DNA damage, cell cycle checkpoint, genomic instability

\section{Background}

Heterozygosity leads to haploinsufficiency for proteins. Heterozygous animals for one gene show similar appearance and life-span as the wild type in normal conditions since one of the alleles is still functional. However, heterozygous animals display high tumor incidence when exposed accidentally and severely to mutagens, such as high doses of ionizing radiation. It has been reported that Pten haploinsufficiency accelerated formation of astrocytomas and CDKN1B (also known as p27/Kip1) haploinsufficiency contributed to leukemogenesis $[1,2]$. In general case, an individual may carry more than one heterozygous gene. Heterozygosity for two or more

\footnotetext{
* Correspondence: zhougm@impcas.ac.cn

'Key Laboratory of Heavy Ion Radiation Biology and Medicine, Institute of Modern Physics, Chinese Academy of Sciences, Lanzhou 730000, P. R. China Full list of author information is available at the end of the article
}

genes may multiply the risk of tumor initiation [3-5]. Double heterozygosity of Pten/Trp53 accelerated prostatic tumorigenesis [6]. A strong enhancement in mammary carcinogenesis by Atm/p53 double heterozygosity has also been reported [7].

It was found that genes critical for DNA damage signaling and repair pathways play an important role in tumorigenesis of heterozygosity [8-11]. ATM is both a sensor and transducer of DNA damage. The protein is rapidly activated by damage-induced autophosphorylation on ser ${ }^{1981}$ followed by dissociation into an active monomer $[12,13]$. Once activated, it phosphorylates a series of downstream substrates including Nbs1, Chk1, Chk2, p53, etc., and finally activates cell cycle checkpoints, DNA repair as well as apoptosis [14]. It has been reported that Atm heterozygosity is linked with the induction of cataracts and tumorigenesis [15-18]. BRCA1 is also a multifunctional

\section{Biomed Central}


protein functioning in G2/M checkpoint and plays a central role in DNA repair $[19,20]$. The protein reduces the expression, phosphorylation and cellular localization of cdc25c and cdc2/cyclinB kinase, increases the expression of Wee1 kinase and 14-3-3 $\sigma$ to inhibit the G2-M transition. People who are heterozygous for Brca1 have a high risk of developing breast and ovarian cancer [21]. Contribution of Brca1 heterozygosity to tumor susceptibility has been reported [22,23].

In some cases, a multifunctional gene may be involved in more than one pathway when cells are exposed to exogenous stress. This makes the mechanisms of heterozygosity-related tumorigenesis more complicated. For example, both ATM and BRCA1 are part of BASC (BRCA1-associated genome surveillance complex), which is involved in recognition and repair of aberrant DNA structures [24,25]. DNA damage-induced ATM activation requires a coordinated assembly of BRCA1, BAAT1, and ATM [26], meanwhile BRCA1 is a substrate of ATM and its phosphorylation by ATM is critical for responding to double-strand breaks and G2/M checkpoint [27-29]. Epidemiological statistics reveals that reduction of ATM is common in BRCA1/2-deficient breast cancer [30]. Breast cancer in AT family is 1.5-14 folds higher [31-34]. Therefore, ATM and BRCA1 interact with each other and their association could be enhanced by mutagen treatment. Both of Atm and Brcal are multifunctional genes involved in DNA repair pathways and cell cycle checkpoints. The risk of tumorigenesis may be increased in Atm/Brca1 double heterozygote.

Up to now, there are very few literatures on Atm/ Brcal double heterozygosity and their contribution to tumor initiation. In 2005, Bowen et al. reported that Atm heterozygosity increased the severity of mammary gland tumors in the BRCA1-defficient mouse [35]. Our previous work has demonstrated that double heterozygosity for Atm and Brcal leads to higher cell transformation rate than single heterozygosity [36], but the underlying mechanisms have not been fully understood yet. In the present study, mouse embryonic fibroblast (MEF) cells of wild type, Atm or Brca1 single heterozygosity, and Atm/Brcal double heterozygosity were used to develop the correlation of heterozygosity for Atm and/or Brca1 and tumorigenesis. A series of pathways including DNA damage recognition and repair, cell cycle checkpoints, genomic instability, and transformation frequency were investigated to identify the possible underlying mechanisms after the four genotypes of cells were exposed to photon radiation.

\section{Methods}

\section{Cell culture}

Four genotypes of MEF cells (wild type, ATMwt/ BRCA1wt; Atm single heterozygote, ATMhz/BRCA1wt;
Brca1 single heterozygote, ATMwt/BRCA1hz; and Atm/ Brca1 double heterozygote, ATMhz/BRCA1hz) were obtained from the Center for Radiological Research, Columbia University Medical Center, New York. Cells were cultured with DMEM high glucose (Gibco, Grand Island, NY, USA) supplemented with 15\% FBS (HyClone, Logan, UT, USA).

\section{Irradiation}

A GammaCell $40{ }^{137} \mathrm{Cs}$ irradiator $(0.82 \mathrm{~Gy} / \mathrm{min})$ of Columbia University and a $6 \mathrm{MV}$ X-ray generator (2 Gy/min) of Gansu Academy of Medical Sciences were used for the irradiation of the cells.

\section{Cell survival and neoplastic transformation}

Anchorage-independent growth was conducted as described previously with slight modification [37]. Neoplastic transformation was assessed in a non-permissive condition of soft agar. Briefly, $\varphi 60 \mathrm{~mm}$ dishes were previously plated with $8 \mathrm{ml}$ base agar layer prepared from a mixture of $68 \mathrm{ml}$ 1.25\% Bacto-agar, $17 \mathrm{ml}$ tryptose phosphate broth (Sigma, St. Louis, MO, USA), $17 \mathrm{ml}$ FBS and $68 \mathrm{ml}$ double-strength of DMEM medium. After the mixture was solidified, $2.0 \times 10^{4}$ cells which had been exposed to $2 \mathrm{~Gy}$ of photons and incubated for one week were added to $2 \mathrm{ml}$ of agar mixture prepared as above, and then plated on the agar base. Immediately after plating, cell clumps in each dish were marked and scored to avoid mis-counted as colonies. Cells were grown for 2 months in a $\mathrm{CO}_{2}$ incubator with saturated humidity. During this period $1 \mathrm{ml}$ medium were added periodically to each dish. Colonies were counted as transformants using a dissecting microscope. For cell survival, similar procedure was followed but in a permissive condition. Specifically, 1.25\% Bacto-agar was replaced with lowmelting-point agarose and tryptose phosphate broth was replaced with distilled water. Cell survival was assessed right after cells were exposed to irradiation.

\section{$\gamma \mathrm{H} 2 \mathrm{AX}$ foci}

Exponentially growing MEF cells of four genotypes were plated in four-well slide chambers (Lab-Tek, Naperville, IL, USA) at a density of $8 \times 10^{3}$ cells/well. Sixteen hours later, the cells were irradiated with 0.2 and 0.5 Gy of photons, fixed for $10 \mathrm{~min}$ in $4 \%$ paraformaldehyde, permeabilized for $5 \mathrm{~min}$ in methanol at $-20^{\circ} \mathrm{C}$, blocked for $1 \mathrm{~h}$ with $5 \%$ skim milk, and stained with mouse anti$\gamma \mathrm{H} 2 \mathrm{AX}$ antibody (Upstate Biotechnology, Lake Placid, NY, USA) for $2 \mathrm{~h}$. The bound antibody was visualized using Alexa Fluor ${ }^{\circledR} 488$ anti-mouse antibody (Molecular Probes, Eugene, OR, USA), and cell nuclei were counterstained with PI/RNase solution (PharMingen, San Jose, CA, USA). Slides were observed under a confocal laser scanning microscope (Nikon, Tokyo, Japan). At 
least 100 cells were scored for each sample, and the average number of foci per cell was calculated.

\section{Comet Assay}

DNA damage and repair were evaluated with alkaline comet assay according to the report of Olive et al with minor modifications [38]. In brief, single cells were harvested and re-suspended in DMEM medium containing $10 \% \mathrm{FBS}$ at a concentration of $1 \times 10^{6}$ cells $/ \mathrm{ml}$. Cell suspension was mixed with $0.5 \%$ low meltingpoint agarose (Amresco, Solon, OH, USA) (1:3, V/V). The mixture was layered on each glass slide with precoated $0.5 \%$ LE agarose. After exposed to $10 \mathrm{~Gy}$ of photons, the samples were gently immersed into freshly prepared lysis solution $(2.5 \mathrm{M} \mathrm{NaCl}, 10 \mathrm{mM}$ Tris, $1 \%$ sodium lauryl sarcosinate, $100 \mathrm{mM}$ EDTA, 1\% Triton-100, and 10\% DMSO) for $1.5 \mathrm{~h}$ and transferred to electrophoresis tank. After 20 min of DNA unwinding in buffer ( $1 \mathrm{mM}$ EDTA, $300 \mathrm{mM} \mathrm{NaOH}, \mathrm{pH}>13)$, electrophoresis was performed in the same buffer $(20$ min, $20 \mathrm{~V}, 300 \mathrm{~mA}$ ). The samples were neutralized with 0.4 M Tris- $\mathrm{HCl}(\mathrm{pH} 7.5)$ and air-dried after a brief fixation with $70 \%$ ethanol.

Individual cells were visualized with ethidium bromide staining and photographed under a fluorescence microscope. For each sample, 200 comets were analyzed with CASP software [39].

\section{Cell cycle}

Cell cycle distribution was monitored with a flow cytometer as described previously [40]. MEF cells exposed to $5 \mathrm{~Gy}$ of photons were post-incubated for various times, harvested, fixed with $70 \%$ pre-chilled ethanol for over $24 \mathrm{~h}$ at $-20^{\circ} \mathrm{C}$, re-suspended in PBS, and treated with PI/RNase solution. Cell cycle distribution of 10,000 cells for each genotype was analyzed with CellQuest pre-stored in FACScan flow cytometer (Beckon-Dickinson, CA, USA).

\section{Micronuclei}

Exponentially growing MEF cells of four genotypes were plated in 12-well plates at a density of $3 \times 10^{5}$ cells/well. For each well, $3 \mu \mathrm{g} / \mathrm{ml}$ of cytochalasin B (Sigma, St. Louis, MO, USA) was added after cells were exposed to 2 Gy of photons. Twenty-four hours later, cells were washed with PBS and fixed with methanol-glacial acetic acid (9:1, V/V). After stained with $3 \mu \mathrm{g} / \mathrm{ml}$ Acridine Orange, at least 500 of binucleated cells for each genotype were counted to obtain the frequency of micronuclei.

\section{Statistical Analysis}

All data were presented as mean $\pm \mathrm{SE}$ of at least three independent experiments. Students' $t$-test was used to evaluate statistically significant.

\section{Results}

\section{Transformation}

Anchorage-independent growth assay was carried out to measure cell survival of four kinds of MEF cells in permissive condition right after the cells were exposed to 2 Gy of photons and to measure neoplastic transformation in non-permissive condition 1 week after irradiation. Results showed that 2 Gy of photons inactivated the four kinds of MEF cells almost equally (Figure 1A). However, induced cell transformation was in a genotype-dependent manner (Figure 1B). For sham irradiated sample, an average transformation frequency of $8.86 \pm$ $0.14,6.31 \pm 1.66,8.69 \pm 1.35$, and $10.50 \pm 1.64\left(\times 10^{-5}\right.$, transformants per $10^{5}$ viable cells) was obtained for ATMwt/BRCA1wt, ATMwt/BRCA1hz, ATMhz/ BRCA1wt, and ATMhz/BRCA1hz, respectively. No significant differences were observed. Upon photon irradiation, dramatically increased yields of anchorageindependent colonies were observed in the four kinds of cells in a genotype-dependent manner. Remarkably high transformation frequency was obtained in double heterozygous cells while wide type cells presented the lowest transformation frequency and single heterozygous cells presented the middle ones. This result confirms that double heterozygosity is confronted with higher tumorigenesis risk than single one.

\section{DNA damage and repair}

In this study, we used two methods to observe DNA damage and repair ability of cells heterozygous for Atm and/or Brca1. One was $\gamma \mathrm{H} 2 \mathrm{AX}$ focus formation by
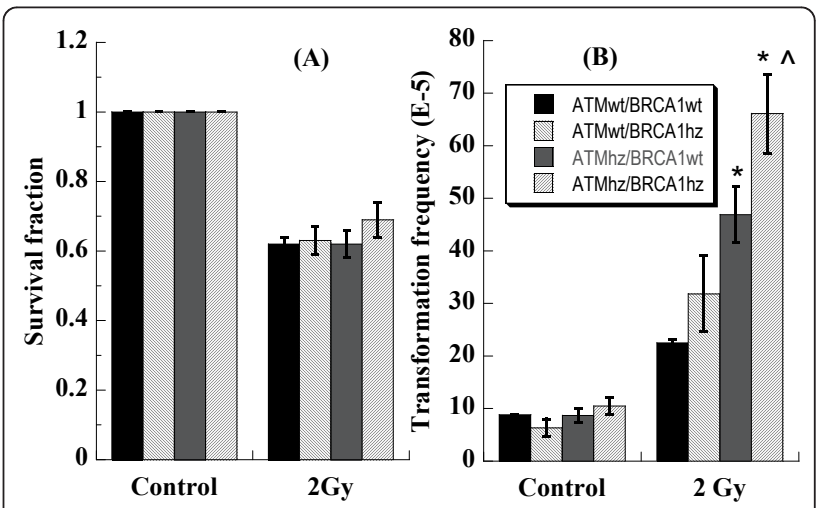

Figure 1 Anchorage-independent growth levels of four kinds of MEF cells. After cells were exposed to $2 \mathrm{~Gy}$ of photons, permissive soft-agar assay was performed immediately to assess cell survival (Panel A) and 1 week later, non-permissive soft-agar assay were performed to assess neoplastic transformation (Panel B). Transformants were visually scored under a dissecting microscope. Data are from four independent experiments. ${ }^{*}$ indicates the significant difference $(p<0.05)$ compared with ATMwt/BRCA1wt cells and $\wedge$ indicates the significant difference $(p<0.05)$ compared with ATMwt/BRCA1 hz cells experienced the same treatment. 
immunofluorescent staining to visualize DSBs [41] and the other was alkaline comet assay to quantify total DNA damage.

Representative pictures of $\gamma \mathrm{H} 2 \mathrm{AX}$ foci were shown as Figure 2. Consistent with other reports, $\gamma \mathrm{H} 2 \mathrm{AX}$ foci were formed in a dose- and time- dependent manner (Figure 3). The dose response of $\gamma \mathrm{H} 2 \mathrm{AX}$ focus formation was scored at $30 \mathrm{~min}$ post-irradiation. The foci per cell induced by 0.5 Gy of photons did not show statistical differences in all kinds of MEF cells. However, significant differences were observed when cells were exposed to 0.2 Gy of photons. The lowest number was in double heterozygous cells. This genotype-dependent manner was confirmed by the kinetics of focus formation. The number of $\gamma \mathrm{H} 2 \mathrm{AX}$ foci increased very rapidly after irradiation even during the very first 2 min required for sample preparation. The number of foci in wild type cells reached to the maximum at $15 \mathrm{~min}$ and then decreased gradually. Atm single heterozygous cells, Brcal single heterozygous cells and Atm/Brcal double heterozygous cells spent as long as $60 \mathrm{~min}$ before the approach to the maximum. It indicates that the response of wild type cells to DSBs induced by ionizing radiation is faster than the response of heterozygous cells. The recognition of DNA damage is delayed in heterozygote.

In previous studies, we observed significantly higher background of DNA damage in heterozygous cells [36]. We observed the induction and repair of DNA damage

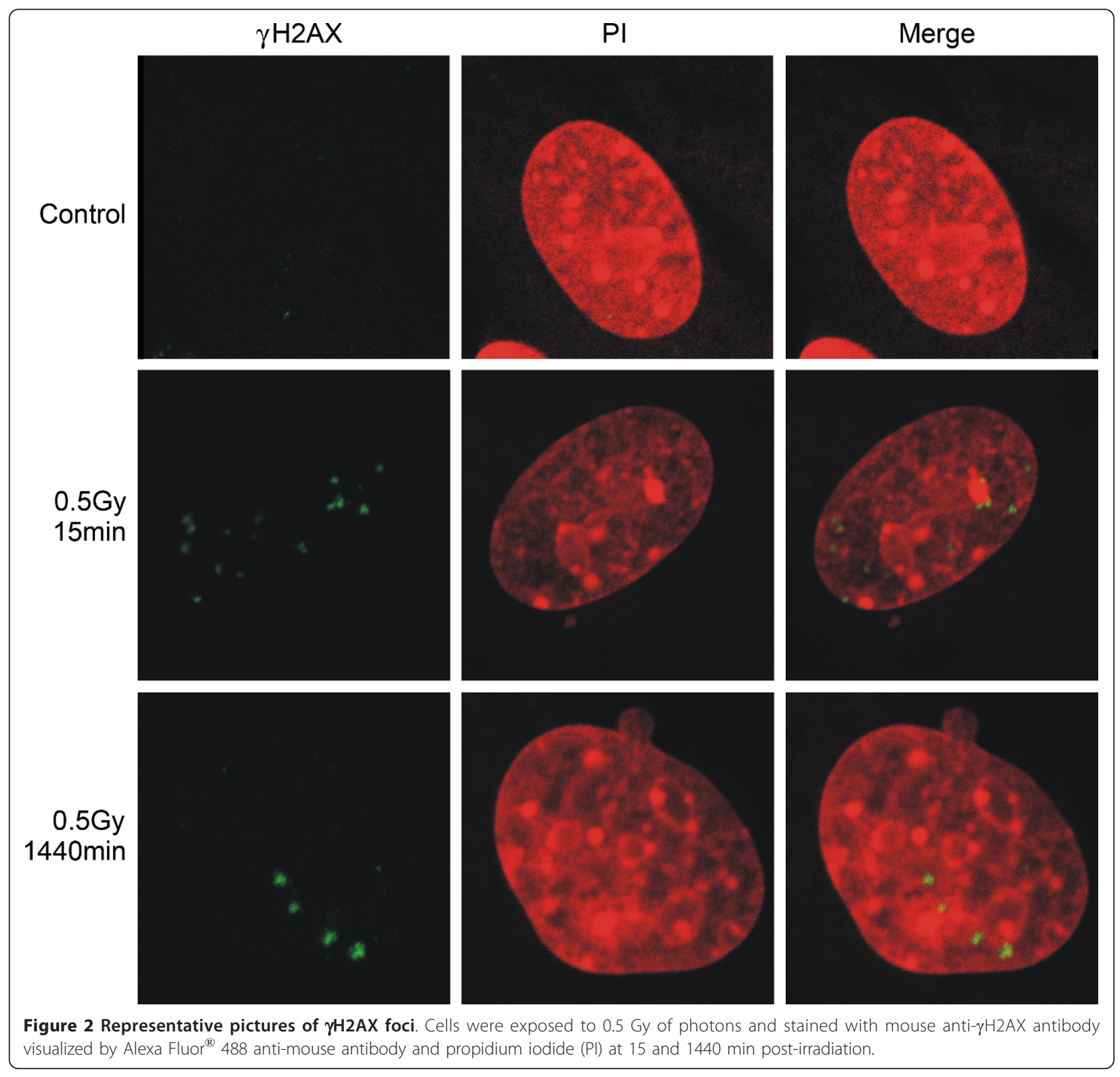




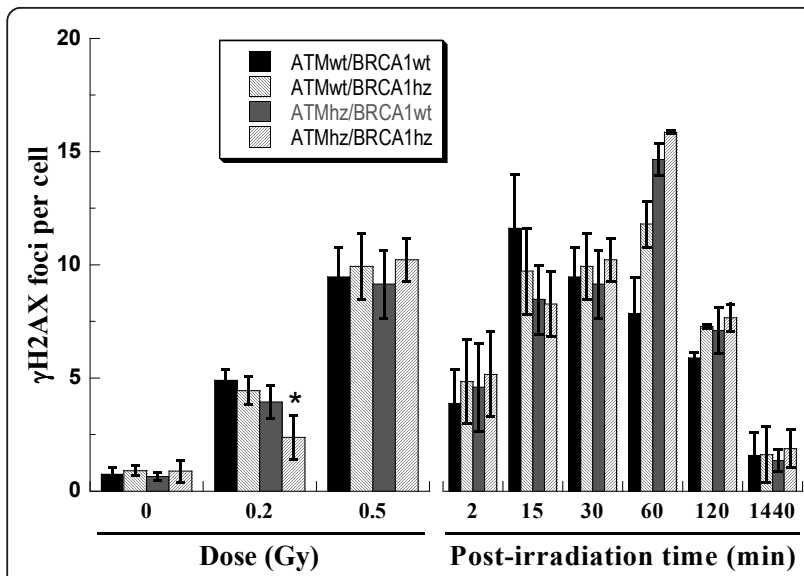

Figure 3 Quantitative detection of DSBs by counting $\gamma \mathrm{H} 2 \mathrm{AX}$ foci. Dose response (left) and kinetics (right) of $\gamma \mathrm{H} 2 \mathrm{AX}$ focus formation. Samples for dose response were fixed at $30 \mathrm{~min}$ after irradiation and kinetics was for 0.5Gy of photons. * indicates the significant difference $(p<0.05)$ compared with ATMwt/BRCA1wt cells exposed to $0.2 \mathrm{~Gy}$ of photons.

induced by photon irradiation in this study with the same technology, comet assay. As shown in Figure 4, without post-irradiation incubation, DNA damage induced in wild type cells was significantly lower than that in other three kinds of cells $(\mathrm{p}<0.01)$. It might be due to the rapid repair processes that occurred during comet assay preparation. At 240 min post-incubation, DNA damage in each cell type decreased to background level. However, the residual DNA damage in double heterozygous cells was the highest one among the four

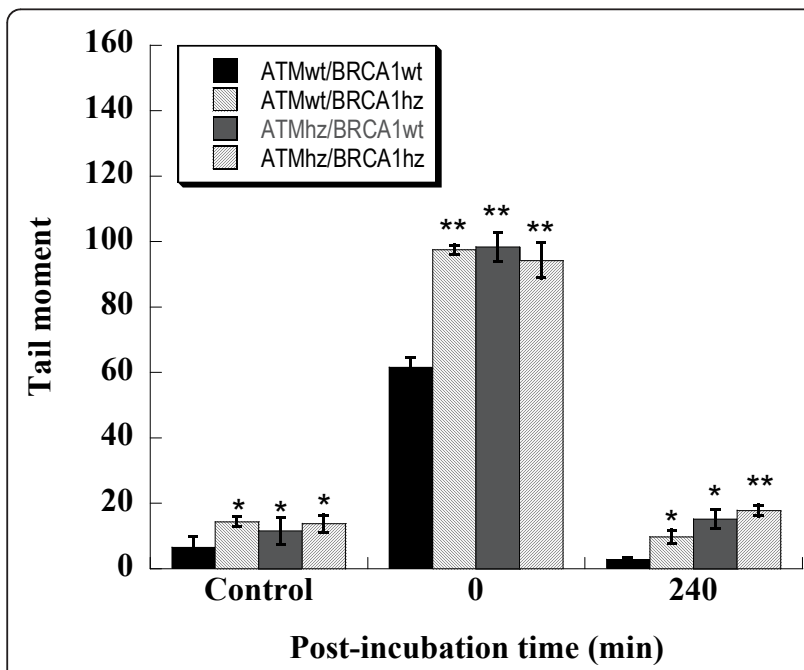

Figure 4 Total DNA damage measured with alkaline comet assay in four kinds of MEF cells at different time course. Data were a pool of three independent experiments and totally 200 cells were scored. ${ }^{*}$ and ${ }^{* *}$ indicate the significant difference compared with ATMwt/BRCA1wt cells experienced the same treatment and same post-incubation ( ${ }^{*}$ for $p<0.05$ and ${ }^{* *} p<0.01$ ). kinds of MEF cells, and the residual DNA damages in single heterozygote were also significantly higher than that in wild type cells. These results suggest that DNA repair may be delayed in heterozygote and DNA repair ability may be the lowest in double heterozygote.

\section{Cell cycle dynamics}

As expected, 5 Gy of photons induced G2/M block in all genotypes. Notably the induction of G2/M block was similar in all the genotypes (Figure 5). However, different genotypes followed different dynamics of G2/M-phase cell release. Wild type cells overcame the G2/M arrest in 13 hours. Brca 1 single heterozygous cells overcame that block earlier while Atm single heterozygous cells later. Interestingly, single heterozygosity results in disturbed cell cycle control while double heterozygous cells showed a similar cell cycle dynamics to the wild type cells.

\section{Genomic instability}

Cytochalasin-blocked micronucleus assay is a widely used method for the detection of genomic instability. The micronuclei per binucleated cell induced by 2 Gy of photon in each kind of cells were not the same (Figure 6). The highest micronucleus frequency was observed in double heterozygous cells while the lowest in wild type cells. This result demonstrates that micronucleus formation can be obviously enhanced in Atm/Brcal double heterozygous cells, suggesting an impairing of genomic stability.

\section{Discussion}

Heterozygosity results in haploinsufficiency. Haploinsufficient animals or cells for DNA-repair related proteins
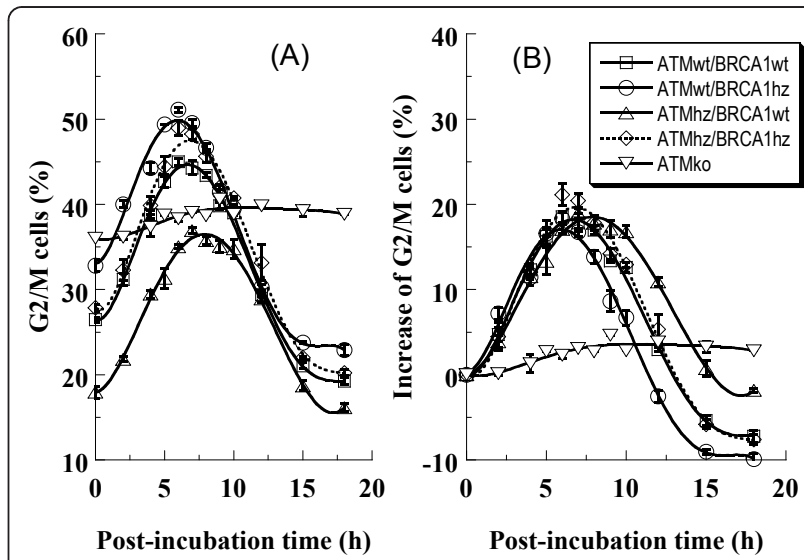

Figure 5 Cell cycle distribution in MEF cells exposed to 5 Gy of photons. Kinetics of G2/M block based on original data (Panel A) and optimized dada in which the control level of G2/M-phase cells was correspondingly subtracted from the proportion of G2/M-phase cells of each sample (Panel B). Data are pooled from three independent experiments. 


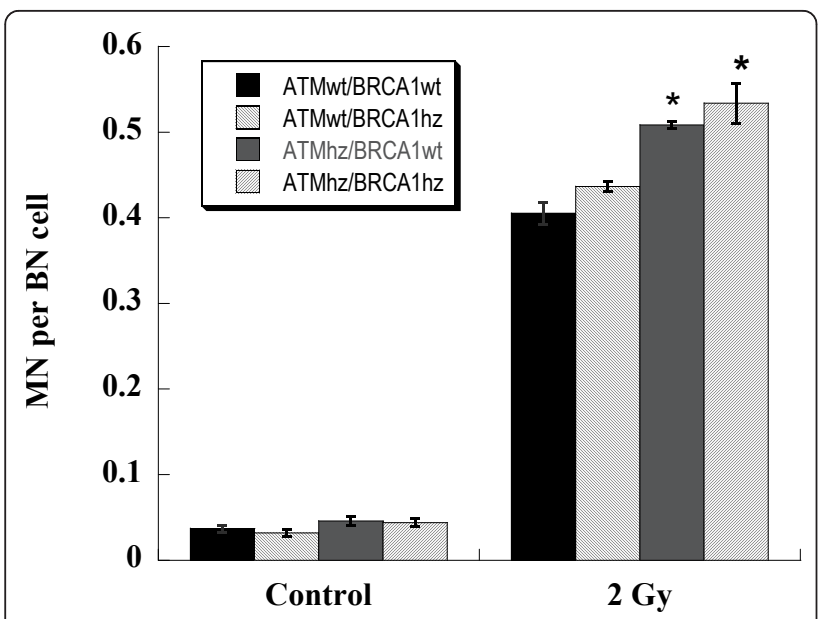

Figure 6 Induction of micronuclei in MEF cells exposed to 2 Gy of photons. Individual cells were visualized with Acridine Orange staining and micronuclei (MN) per binucleated cell (BN) were score under fluorescence microscope. More than 500 BN cells were counted for each sample. Data were pooled from three independent experiments. ${ }^{*}$ indicates the significant difference $(p<$ 0.05) compared with ATMwt/BRCA1wt cells exposed to the same dose of photons.

appear normal under stationary conditions. However, high tumor incidence or transformation rate is observed when they are exposed severely and accidentally to exogenous stimuli. It is very possible that protein products from one allele are not enough for the detection and repair of damage induced by the exogenous factors. On the other hand, cell cycle checkpoint is activated to earn time for damage repair. If the heterozygous gene takes part in the cell cycle checkpoint pathway, cell cycle checkpoint might also be negatively impacted and cells with un-repaired damage might escape the monitor and pass the remained lesions to their daughter cells, which have high potential for genomic instability, transformation, and consequently high risk of tumorigenesis.

\section{How does haploinsufficiency impact the processes of DNA damage recognition?}

In 2006, Smilenov proposed a theory of temporal biological network to explain the mechanisms underlying the link between heterozygous Atm and/or Rad9 and tumor predisposition, in which a temporal network assembled by both gene products and DNA damage caused by ionizing radiation is thought to be critical to activate apoptosis pathways [42]. According to this theory, ATM-dependent local network is a critical element in a cell responding to DNA damage. The number of local networks assembled on the damage points determines the generated signal level, which in turn controls the induction of apoptosis. Theoretically, there is no problem for wide type cells to recognize DNA damage induced by high-dose and low-dose radiation. In the case of heterozygosity and high-dose radiation, heterozygous cells can recognize DNA damage due to enough DNA damage even though there are no enough gene products to work efficiently. However, in the case of heterozygosity and low-dose radiation, since neither gene products nor DNA damage is enough, limited number of local networks might be assembled to trigger apoptosis. Some of the damages will not be detected, and apoptotic response can not be fully activated. Heterozygous cells with lesions might survive the stimulation, which consequently results in tumor initiation.

In the present study, we employed $\gamma \mathrm{H} 2 \mathrm{AX}$ foci to observe the DNA recognition because it is a rapid process and sensitive method. After irradiation, $\gamma \mathrm{H} 2 \mathrm{AX}$ foci usually appear in 30 seconds and increase until a plateau is reached by 10-30 minutes [43]. The level of the plateau is proportional to radiation dose [44]. Along with further incubation, the number of foci per cell decreases due to DNA repair. Therefore, the height of plateau may reflect the original damage level, and the formation process of $\gamma \mathrm{H} 2 \mathrm{AX}$ foci may represent the recognition of DNA damage. As shown in Figure 3, the genotypedependent difference of $\gamma \mathrm{H} 2 \mathrm{AX}$ foci implied that some DNA damage induced by 0.2 Gy photons could not be well recognized in double heterozygosity. Furthermore, it took heterozygous cells longer time to respond to radiation as confirmed by the time kinetics. Thus, Simlenov's hypothesis can be broadened to more biological processes. In the case of heterozygosity and low-dose radiation, no enough temporary biological networks are assembled to activate a series of pathways, such as damage recognition, DNA repair, apoptosis, and so on. Double heterozygosity leads to the alleviated assembly of local networks. One possible pathway of those heterozygous cells with un-repaired damage is to go to reproductive death, and another is to escape from cell cycle monitoring, apoptosis pathway, and consequently transfer the lesions to daughter cells through mitosis.

\section{How does haploinsufficiency impact cell cycle checkpoints?}

ATM activates a series of DNA-repair related factors [27] and cell cycle checkpoints factors [14,45]. BRCA1 is one of the key proteins participating in a common pathway to facilitate orderly homologous recombination and thereby maintaining genomic stability [20]. Therefore, insufficient products of these two genes supposedly lead to incompletely functional cell cycle checkpoints.

In our experiments, Atm-knockout cells have a high proportion of $\mathrm{G} 2 / \mathrm{M}$ phase, which is in consistent with the other report [46]. As shown in Figure 5, Atm knockout cells exposed to 5 Gy of photons had prolonged G2 arrest, which implies the important role of ATM in G2- 
$\mathrm{M}$ transition. Then, what is the possible consequence of the delay of G2-arrest release in cells heterozygous for Atm? Since ATM is a sensor detecting DNA damage and also a transducer activating downstream genes to repair the damage, its insufficient expression theoretically reduces the efficiency of DNA repair. The extra repair time obtained from the prolonged G2 arrest could not compensate this inefficiency, which can be concluded from the results of DNA repair measured by alkaline comet assay. As shown in Figure 4, the wild type cells have the most efficient repair ability, and the double heterozygote has the least. On the other hand, a very possible consequence of the abrogation of G2 arrest in cells heterozygous for Brcal is that some cells with un-repaired DNA damage escape the cell cycle monitoring and transfer the damage to their offspring.

\section{Atm and Brca1 heterozygosity enhances transformation frequency and increases the risk of tumorigenesis}

Since Atm/Brcal double heterozygosity results in low apoptosis [36], a very possible consequence is that residual DNA damage escaped from cell cycle checkpoints arouses genomic instability in the offspring of heterozygous cells. As shown in Figure 6, micronuclei induced by photons were genotype-dependent. The highest micronucleus frequency was obtained in double heterozygote while the lowest in wild type cells.

High sensitivity to transformation and low level of DNA damage repair were reported in double heterozygote induced by radiation [36, 47 and 48]. Our results confirmed that heterozygosity of either Atm or Brcal resulted in increased cell transformation and Atm/Brcal double heterozygosity enhanced the transformation frequency significantly (Figure 1).

These results imply the positive correlation of genomic instability with cell transformation and the consequently high frequency of tumor initiation in double heterozygote.

\section{Conclusions}

Taken together, haploinsufficiency of either ATM or BRCA1 negatively impacts a series of pathways including delayed DNA damage recognition, disturbed cell cycle checkpoint, incomplete DNA repair, increased genomic instability and transformation frequency. The quantity of critical proteins such as ATM and BRCA1 plays an important role in determination of the fate of cells exposed to ionizing radiation and Atm/Brcal double heterozygosity increases the risk of tumorigenesis. These findings not only provide an experimental proof to Smilenov's hypothesis and broaden it to more biological processes, but also benefit understanding of the individual susceptibility to tumor initiation.

\section{List of abbreviations}

Atm: ataxia telangiectasia mutated; Brca1: breast cancer 1; MEF: mouse embryonic fibroblast; SE: standard error; PCR: polymerase chain reaction; DMEM: Dulbecco's Modified Eagle Medium; FBS: fetal bovine serum; PBS: phosphate buffered saline.

\section{Acknowledgements}

We wish to thank Dr. Tom Hei from the Center for Radiological Research, Columbia University Medical Center, New York, NY 10032, USA, for fruitful discussions. This work was supported by grants from the Major State Basic Research Development Program of China (973 Program, No. 2010CB834201) and the Hundred Talent Program of the Chinese Academy of Sciences (No. 0760140BRO), US Department of Energy (No. DE-FG02-03ER63629), NASA (No. NAG 9-1519), and PO1-CA97403 Project 5.

\section{Author details}

${ }^{1}$ Key Laboratory of Heavy Ion Radiation Biology and Medicine, Institute of Modern Physics, Chinese Academy of Sciences, Lanzhou 730000, P. R. China. ${ }^{2}$ Center for Radiological Research, Columbia University Medical Center, New York, NY 10032, USA. ${ }^{3}$ Graduate School of Chinese Academy of Sciences, Beijing 100049, China.

\section{Authors' contributions}

GZ and LBS conceived the study and participated in its design. LBS isolated and provided the heterozygous cells. FS, LZ, WT and ND carried out the YH2AX foci, comet, cell cycle, micronuclei and transformation assay. JF participated in coordination and drafted the manuscript. All authors read and approved the final manuscript.

\section{Competing interests}

The authors declare that they have no competing interests.

Received: 17 March 2011 Accepted: 17 August 2011

Published: 17 August 2011

\section{References}

1. Kwon CH, Zhao D, Chen J, Alcantara S, Li Y, Burns DK, Mason RP, Lee EY, Wu H, Parada LF: Pten haploinsufficiency accelerates formation of highgrade astrocytomas. Cancer Res 2008, 68:3286-3294.

2. Le Toriellec E, Despouy G, Pierron G, Gaye N, Joiner M, Bellanger D, Vincent-Salomon A, Stern MH: Haploinsufficiency of CDKN1B contributes to leukemogenesis in T-cell prolymphocytic leukemia. Blood 2008, 111:2321-2328.

3. Kucherlapati M, Yang K, Kuraguchi M, Zhao J, Lia M, Heyer J, Kane MF, Fan K, Russell R, Brown AM, Kneitz B, Edelmann W, Kolodner RD, Lipkin M, Kucherlapati R: Haploinsufficiency of Flap endonuclease (Fen1) leads to rapid tumor progression. Proc Natl Acad Sci USA 2002, 99:9924-9929.

4. Kleiman NJ, David J, Elliston CD, Hopkins KM, Smilenov LB, Brenner DJ, Worgul BV, Hall EJ, Lieberman HB: Mrad9 and atm haploinsufficiency enhance spontaneous and X-ray-induced cataractogenesis in mice. Radiat Res 2007, 168:567-573.

5. Izeradjene K, Combs C, Best M, Gopinathan A, Wagner A, Grady WM, Deng CX, Hruban RH, Adsay NV, Tuveson DA, Hingorani SR: Kras(G12D) and Smad4/Dpc4 haploinsufficiency cooperate to induce mucinous cystic neoplasms and invasive adenocarcinoma of the pancreas. Cancer Cell 2007, 11:229-243.

6. Couto SS, Cao M, Duarte PC, Banach-Petrosky W, Wang S, Romanienko P, Wu H, Cardiff RD, Abate-Shen C, Cunha GR: Simultaneous haploinsufficiency of Pten and Trp53 tumor suppressor genes accelerates tumorigenesis in a mouse model of prostate cancer. Differentiation 2009, 77:103-111.

7. Umesako S, Fujisawa K, liga S, Mori N, Takahashi M, Hong DP, Song CW, Haga S, Imai S, Niwa O, Okumoto M: Atm heterozygous deficiency enhances development of mammary carcinomas in p53 heterozygous knockout mice. Breast Cancer Res 2005, 7:R164-170.

8. Bertout JA, Patel SA, Fryer BH, Durham AC, Covello KL, Olive KP, Goldschmidt MH, Simon MC: Heterozygosity for hypoxia inducible factor 1alpha decreases the incidence of thymic lymphomas in a p53 mutant mouse model. Cancer Res 2009, 69:3213-3220. 
9. Barlow C, Eckhaus MA, Schaffer AA, Wynshaw-Boris A: Atm haploinsufficiency results in increased sensitivity to sublethal doses of ionizing radiation in mice. Nat Genet 1999, 21:359-360.

10. Bartek J, Lukas J, Bartkova J: DNA damage response as an anti-cancer barrier: damage threshold and the concept of 'conditional haploinsufficiency'. Cell Cycle 2007, 6:2344-2347.

11. Smilenov LB, Brenner DJ, Hall EJ: Modest increased sensitivity to radiation oncogenesis in ATM heterozygous versus wild-type mammalian cells. Cancer Res 2001, 61:5710-5713.

12. Bakkenist CJ, Kastan MB: DNA damage activates ATM through intermolecular autophosphorylation and dimer dissociation. Nature 2003, 421:499-506

13. Kozlov S, Gueven N, Keating K, Ramsay J, Lavin MF: ATP activates ataxiatelangiectasia mutated (ATM) in vitro. Importance of autophosphorylation. J Biol Chem 2003, 278:9309-9317

14. Falck J, Mailand N, Syljuasen RG, Bartek J, Lukas J: The ATM-Chk2-Cdc25A checkpoint pathway guards against radioresistant DNA synthesis. Nature 2001, 410:842-847.

15. Hall EJ, Worgul BV, Smilenov L, Elliston CD, Brenner DJ: The relative biological effectiveness of densely ionizing heavy-ion radiation for inducing ocular cataracts in wild type versus mice heterozygous for the ATM gene. Radiat Environ Biophys 2006, 45:99-104

16. Worgul BV, Smilenov L, Brenner DJ, Junk A, Zhou W, Hall EJ: Atm heterozygous mice are more sensitive to radiation-induced cataracts than are their wild-type counterparts. Proc Natl Acad Sci USA 2002, 99:9836-9839.

17. Lu S, Shen K, Wang Y, Santner SJ, Chen J, Brooks SC, Wang YA: Atmhaploinsufficiency enhances susceptibility to carcinogen-induced mammary tumors. Carcinogenesis 2006, 27:848-855.

18. Worgul BV, Smilenov L, Brenner DJ, Vazquez M, Hall EJ: Mice heterozygous for the ATM gene are more sensitive to both X-ray and heavy ion exposure than are wildtypes. Adv Space Res 2005, 35:254-259.

19. Yarden RI, Pardo-Reoyo S, Sgagias M, Cowan KH, Brody LC: BRCA1 regulates the $\mathrm{G} 2 / \mathrm{M}$ checkpoint by activating Chk1 kinase upon DNA damage. Nat Genet 2002, 30:285-289.

20. Powell $S N$, Kachnic LA: Roles of BRCA1 and BRCA2 in homologous recombination, DNA replication fidelity and the cellular response to ionizing radiation. Oncogene 2003, 22:5784-5791.

21. Cousineau I, Belmaaza A: BRCA1 haploinsufficiency, but not heterozygosity for a BRCA1-truncating mutation, deregulates homologous recombination. Cell Cycle 2007, 6:962-971.

22. Latimer JJ, Rubinstein WS, Johnson JM, Kanbour-Shakir A, Vogel VG, Grant SG: Haploinsufficiency for BRCA1 is associated with normal levels of DNA nucleotide excision repair in breast tissue and blood lymphocytes. BMC Med Genet 2005, 6:26-37.

23. Jeng YM, Cai-Ng S, Li A, Furuta S, Chew H, Chen PL, Lee EY, Lee WH: Brca1 heterozygous mice have shortened life span and are prone to ovarian tumorigenesis with haploinsufficiency upon ionizing irradiation. Oncogene 2007, 26:6160-6166.

24. Wang Y, Cortez D, Yazdi P, Neff N, Elledge SJ, Qin J: BASC, a super complex of BRCA1-associated proteins involved in the recognition and repair of aberrant DNA structures. Genes Dev 2000, 14:927-939.

25. De la Torre C, Pincheira J, Lopez-Saez JF: Human syndromes with genomic instability and multiprotein machines that repair DNA double-strand breaks. Histol Histopathol 2003, 18:225-243.

26. Aglipay JA, Martin SA, Tawara H, Lee SW, Ouchi T: ATM activation by ionizing radiation requires BRCA1-associated BAAT1. J Biol Chem 2006, 281:9710-9718

27. Gatei M, Scott SP, Filippovitch I, Soronika N, Lavin MF, Weber B, Khanna KK: Role for ATM in DNA damage-induced phosphorylation of BRCA1. Cancer Res 2000, 60:3299-3304.

28. Cortez D, Wang Y, Qin J, Elledge SJ: Requirement of ATM-dependent phosphorylation of brca1 in the DNA damage response to doublestrand breaks. Science 1999, 286:1162-1166.

29. Xu B, Kim S, Kastan MB: Involvement of Brca1 in S-phase and G(2)-phase checkpoints after ionizing irradiation. Mol Cell Biol 2001, 21:3445-3450.

30. Tommiska J, Bartkova J, Heinonen M, Hautala L, Kilpivaara O, Eerola H, Aittomaki K, Hofstetter B, Lukas J, von Smitten K, Blomqvist C, Ristimaki A, Heikkila P, Bartek J, Nevanlinna H: The DNA damage signalling kinase ATM is aberrantly reduced or lost in BRCA1/BRCA2-deficient and ER/PR/ ERBB2-triple-negative breast cancer. Oncogene 2008, 27:2501-2506.
31. Andrieu N, Cavaciuti E, Lauge A, Ossian K, Hall J, Stoppa-Lyonnet D: Ataxiatelangiectasia genes and breast cancer risk in a French family study. $J$ Dairy Res 2005, 72:Spec No: 73-80.

32. FitzGerald MG, Bean JM, Hegde SR, Unsal H, MacDonald DJ, Harkin DP, Finkelstein DM, Isselbacher KJ, Haber DA: Heterozygous ATM mutations do not contribute to early onset of breast cancer. Nat Genet 1997, 15:307-310.

33. Geoffroy-Perez B, Janin N, Ossian K, Lauge A, Croquette MF, Griscelli C, Debre M, Bressac-de-Paillerets B, Aurias A, Stoppa-Lyonnet D, Andrieu N: Cancer risk in heterozygotes for ataxia-telangiectasia. Int J Cancer 2001, 93:288-293.

34. Swift $M$, Lukin JL: Breast cancer incidence and the effect of cigarette smoking in heterozygous carriers of mutations in the ataxiatelangiectasia gene. Cancer Epidemiol Biomarkers Prev 2008, 17:3188-3192.

35. Bowen TJ, Yakushiji H, Montagna C, Jain S, Ried T, Wynshaw-Boris A: Atm heterozygosity cooperates with loss of Brca1 to increase the severity of mammary gland cancer and reduce ductal branching. Cancer Res 2005, 65:8736-8746.

36. Su F, Smilenov LB, Ludwig T, Zhou L, Zhu J, Zhou G, Hall EJ: Hemizygosity for Atm and Brca1 influence the balance between cell transformation and apoptosis. Radiat Oncol 2010, 5:15-23.

37. Zhou G, Bennett PV, Cutter NC, Sutherland BM: Proton-HZE-particle sequential dual-beam exposures increase anchorage-independent growth frequencies in primary human fibroblasts. Radiat Res 2006, 166:488-494.

38. Olive PL, Wlodek D, Durand RE, Banath JP: Factors influencing DNA migration from individual cells subjected to gel electrophoresis. Exp Cell Res 1992, 198:259-267.

39. Konca K, Lankoff A, Banasik A, Lisowska H, Kuszewski T, Gozdz S, Koza Z, Wojcik A: A cross-platform public domain PC image-analysis program for the comet assay. Mutat Res 2003, 534:15-20.

40. Zhou G, Kawata T, Furusawa Y, Aoki M, Hirayama R, Ando K, Ito H: Protective effects of melatonin against low- and high-LET irradiation. $J$ Radiat Res 2006, 47:175-181.

41. Sedelnikova OA, Rogakou EP, Panyutin IG, Bonner WM: Quantitative detection of (125)IdU-induced DNA double-strand breaks with gammaH2AX antibody. Radiat Res 2002, 158:486-492.

42. Smilenov LB, Tumor development: Haploinsufficiency and local network assembly. Cancer Lett 2006, 240:17-28.

43. Rogakou EP, Boon C, Redon C, Bonner WM: Megabase chromatin domains involved in DNA double-strand breaks in vivo. J Cell Biol 1999 146:905-916

44. Pilch DR, Sedelnikova OA, Redon C, Celeste A, Nussenzweig A, Bonner WM: Characteristics of gamma-H2AX foci at DNA double-strand breaks sites. Biochem Cell Biol 2003, 81:123-129.

45. Buscemi G, Perego P, Carenini N, Nakanishi M, Chessa L, Chen J, Khanna K, Delia D: Activation of ATM and Chk2 kinases in relation to the amount of DNA strand breaks. Oncogene 2004, 23:7691-7700.

46. Kastan MB, Lim DS: The many substrates and functions of ATM. Nat Rev Mol Cell Biol 2000, 1:179-186.

47. Smilenov LB, Lieberman HB, Mitchell SA, Baker RA, Hopkins KM, Hall EJ: Combined haploinsufficiency for ATM and RAD9 as a factor in cell transformation, apoptosis, and DNA lesion repair dynamics. Cancer Res 2005, 65:933-938.

48. Nieuwenhuis B, Van Assen-Bolt AJ, Van Waarde-Verhagen MA, Sijmons RH, Van der Hout AH, Bauch T, Streffer C, Kampinga HH: BRCA1 and BRCA2 heterozygosity and repair of X-ray-induced DNA damage. Int J Radiat Biol 2002, 78:285-295.

doi:10.1186/1748-717X-6-96

Cite this article as: Wang et al:: Mechanisms of increased risk of tumorigenesis in Atm and Brcal double heterozygosity. Radiation Oncology 2011 6:96. 